\title{
Damage Evolution in Al Wire Bonds Subjected to a Junction Temperature Fluctuation of $30 \mathrm{~K}$
}

\author{
PEARL A. AGYAKWA, ${ }^{1,2}$ LI YANG,${ }^{1}$ ELAHEH ARJMAND,${ }^{1}$ PAUL EVANS, ${ }^{1}$ \\ MARTIN R. CORFIELD, ${ }^{1}$ and C. MARK JOHNSON ${ }^{1}$ \\ 1.-Department of Electrical \& Electronic Engineering, The University of Nottingham, University \\ Park, Nottingham NG7 2RD, UK. 2.—e-mail: pearl.agyakwa@nottingham.ac.uk
}

\begin{abstract}
Ultrasonically bonded heavy $\mathrm{Al}$ wires subjected to a small junction temperature fluctuation under power cycling from $40^{\circ} \mathrm{C}$ to $70^{\circ} \mathrm{C}$ were investigated using a non-destructive three-dimensional (3-D) x-ray tomography evaluation approach. The occurrence of irreversible deformation of the microstructure and wear-out under such conditions were demonstrated. The observed microstructures consist of interfacial and inter-granular cracks concentrated in zones of stress intensity, i.e., near heels and emanating from interface precracks. Interfacial voids were also observed within the bond interior. Degradation rates of 'first' and 'stitch' bonds are compared and contrasted. A correlative microscopy study combining perspectives from optical microscopy with the x-ray tomography results clarifies the damage observed. An estimation of lifetime is made from the results and discussed in the light of existing predictions.
\end{abstract}

Key words: Aluminum, wire bonds, power cycling, reliability, x-ray tomography, high cycle thermal fatigue

\section{INTRODUCTION}

Wire bond cracking and lifting-off under the thermomechanical loading experienced during electrically-driven load-cycling is extensively reported, and is perhaps the dominant life-limiting wear-out mechanism in power electronic modules. The characterisation of wire bond degradation therefore has an important role to play in achieving reliable lifetime models for power modules.

Accuracy of wire bond lifetime prediction is an essential aspect of the reliable design of power electronics components and critical to prognostics and health management. ${ }^{1,2}$ It relies on robust experimental data, which can be sourced from laboratory-based accelerated life tests. With recent developments aimed at increased power density and higher levels of functional integration in power electronics, it is not surprising that applications in which junction temperatures and/or ambient fluctuations exceed $100 \mathrm{~K}$ have begun to dominate

(Received May 10, 2015; accepted April 6, 2016;

published online April 20, 2016) reliability research. ${ }^{3-5}$ However, in the majority of applications, including traction motor drives and wind power converters, ${ }^{6,7}$ small junction temperature ranges are the norm, and accurate lifetime prediction data for such operation regimes is equally important. Rapid degradation of interconnects with catastrophic consequences may be a less frequent occurrence in small $\Delta T$ applications; however, the associated consequences of unavailability and unscheduled maintenance are highly undesirable. Reliable lifetime models for such applications can enable a prognostics and health management approach to asset management, which negates the economic losses associated with unnecessary/premature refits or unscheduled maintenance.

There is a widely held opinion that the thermomechanical stresses imposed by $\Delta T \mathrm{~s}$ of $40 \mathrm{~K}$ and below are so small that there is virtually no wearout, and thus the wire bonds are expected to perform in perpetuum. ${ }^{6,8}$ In ${ }^{6}$ it was suggested that thermomechanical fatigue of $\mathrm{Al}$ wire bonds would follow a trend observed during load-controlled bending fatigue of $99.5 \% \mathrm{Al}$. The belief is that deformation under such small loads is essentially 
'elastic', leading to the conclusion of infinite lifetime under small junction temperature fluctuations. ${ }^{8,9}$ However, the authors are unaware of any experimental evidence to substantiate these hypotheses.

For applications which ordinarily experience "small" temperature fluctuations (i.e. small $\Delta T \mathrm{~s}$ ), accelerated testing is often relied upon to provide service life estimations. However, this approach has a major drawback, namely the existing lack of experimental evidence about degradation mechanisms under such low loads, which are at risk of being concealed by the mechanisms produced by the larger $\Delta T \mathrm{~s}$ often used to generate the information needed. Typically, wire bond lifetimes are interpolated from standard Coffin-Manson curves populated with data generated using much larger $\Delta T \mathrm{~s} .{ }^{10-12}$ This may be an entirely valid approach; nonetheless, its validity needs to be assessed through actual experimental data.

Another important issue regards the limitations of a number of life assessment experimental approaches, such as shear force evaluation. The justification for the use of shear force is that it decreases to reflect the reduction in bonded area that accompanies crack propagation during cycling. However, there is variation in results between different wires because of inherent error in measurement and because of the inherent probabilistic nature of damage evolution. Because each data point originates from a wire bond that is essentially sacrificed, shear testing is insensitive to the very small amounts of degradation which may be typical under small $\Delta T$ mission profiles. Such small changes may be lost in the statistical spread and misconstrued as 'no degradation'. Furthermore, a reduction in shear (and pull) strength may also be attributable to a change in a material's yield strength. This fact becomes even more pertinent if the temperature range is large and involves high junction temperatures equal to or greater than $0.3 T_{\mathrm{m}}$, as significant microstructural restoration can occur. ${ }^{13}$ This means that a wire bond that softens over time but remains adequately intact may be wrongly characterised as lifting off.

Wire bond lifetime evaluation data may also involve forward voltage measurements as a function of the number of cycles. This approach has been shown to lack sufficient sensitivity over the critical wear-out period, as it only begins to detect degradation once lift-offs have already started to occur. ${ }^{14}$ The observation of changes in wire resistance using a four-point probing approach has been proposed as an effective way of monitoring degradation at the wire bond interfaces, ${ }^{15}$ however, no validation through correlation with experimentally observed damage has been shown. Although shear tests and metallurgical cross-sections have greater sensitivity, their destructive nature does not allow the same specimen to be monitored and evaluated over an entire test period. Pertinent information relating to the inherent differences due to different degradation patterns in each wire is therefore forfeited.

Computer tomography (CT) has been around for a couple of decades, but until recently, it was essentially confined to medical diagnostics applications. In recent years, however, suitable, higher energy CT systems have been developed for non-destructive evaluation of the internal structure of engineering materials and structures. ${ }^{16}$ This has been helped significantly by recent developments in computing power. A typical CT system consists of an x-ray source and a detector. Several x-ray images or projections of a sample mounted onto a rotating stage are acquired by a detector. These images are mathematically reconstructed to obtain a threedimensional (3-D) map of the sample. Multiple 'virtual' cross-sections (or slices) can be obtained in any plane of interest. Because a specific specimen can be evaluated repeatedly over its lifetime, an exact picture of the evolution of damage during operation can be obtained and observed threedimensionally. With high enough spatial resolution, near-microstructural characteristics can be observed. In cases such as wire bond degradation under small temperature fluctuations where testing 'to failure' may be infeasible due to time constraints, a prioi knowledge of the condition of the interface obtained through tomography can be evaluated against datasets obtained at later stages of life. Regardless of the temporal resolution of the CT datasets, a reasonable estimation of wear-out rate is possible without the need to test to failure. Additionally, the possibility of three-dimensional scrutiny of degradation as it develops can provide new perspectives and crystallise our understanding of wire bond wear-out. Although wire bond lift-off due to thermal cycling fatigue is well documented, ${ }^{17-19}$ there are complexities in the degradation mechanisms that are not yet fully elucidated. The lack of clarity is attributable to several factors, including the ambiguous nature of the wire bonding mechanism itself, over which there are still a number of views. ${ }^{20-26}$ This is compounded by the fact that the concept of fatigue damage generally lags behind other wear out phenomena in terms of the degree of understanding and consensus of relevant mechanisms of initiation, accumulation, and how these may be quantified. ${ }^{27-29}$ In view of all these factors, the additional insight that can be gained from a 'same sample' $\mathrm{x}$-ray computed tomography study is instrumental.

In this paper, supported by the x-ray CT nondestructive evaluation approach, we examine what actually happens under a small scale temperature fluctuation by observing the same wire bonds over time, and we weigh our observations up against existing knowledge and theories regarding degradation under small junction temperature fluctuations. 


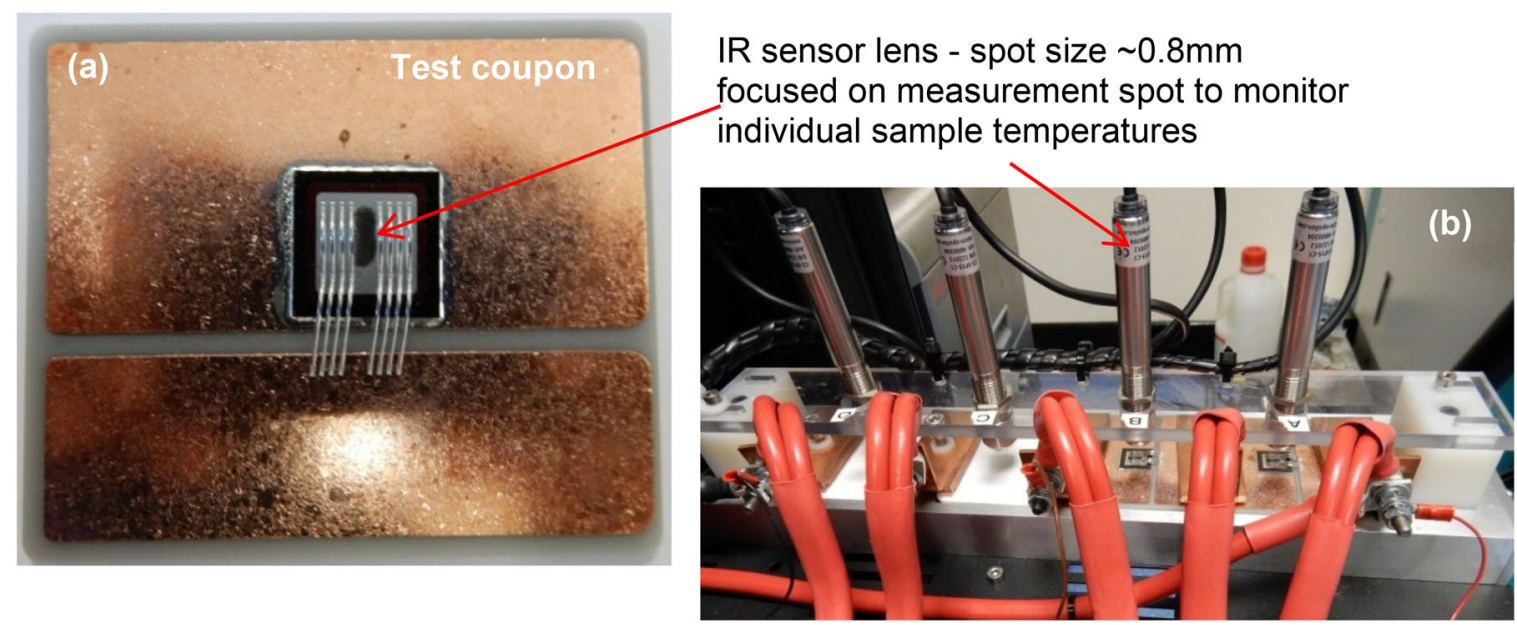

Fig. 1. (a) Test coupon and (b) power cycling set-up.

\section{EXPERIMENTAL PROCEDURES}

The test specimens employed in this study were manufactured externally by Dynex Semiconductor Ltd. They consisted of eight 99.999\% (5N) pure aluminum wires, $375 \mu \mathrm{m}$ in diameter, bonded onto silicon diodes. The silicon diodes had been previously soldered down onto Direct Bonded Copper (DBC) substrates.

\section{Power Cycling Experimental Set-Up}

The power cycling equipment uses a switched current supplied by a constant current power supply to heat a set of sample 'coupons' whilst cooling is provided by a cold-plate connected to a temperaturecontrolled water chiller. Each coupon consists of a single diode die soldered and wire bonded onto a substrate tile, as shown in Fig. 1. A central measurement spot painted on to each diode (an emissivity reference surface) facilitates junction temperature measurement by close-focus infrared (IR) sensor lenses. The heating current is applied or removed automatically when the temperature drops below or rises above specified limits. The heating current is controlled using a set of low-resistance bypass switches (MOSFETs), one in parallel with each coupon, which when activated divert the heating current away from the coupon. The coupon is constantly cooled (at constant temperature) using a heatsink and recirculating chiller. In this experiment, the power cycling regime consisted of applying a constant current of about $32 \mathrm{~A}$. Each cycle had a period of $7 \mathrm{~s}$ and a temperature amplitude of approximately $30 \mathrm{~K}$ from $40^{\circ} \mathrm{C}$ to $70^{\circ} \mathrm{C}$. A snapshot of the temperature profile for the coupons is given in Fig. 2.

\section{X-ray Tomography Imaging and Analysis}

The development of discontinuities (openings, voids, and cracks) at the interface between wire bonds and the silicon dies during power cycling has

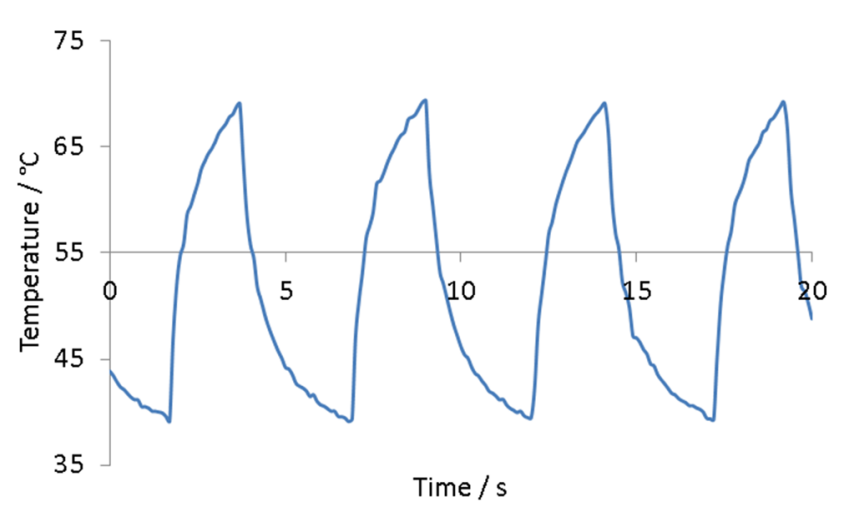

Fig. 2. Snippet of the temperature profile for the test coupons.

been studied. The wire bonds were imaged prior to power cycling (in the "as-bonded" condition) in order to provide a basis for comparison. The same wires were subsequently imaged at several stages between zero and 1.2 million cycles. The work was carried out on an Xradia Zeiss Versa XRM500 CT system with a maximum electron acceleration of $160 \mathrm{kV}$.

A source voltage of $80 \mathrm{kV}$ was used and a $4 \mathrm{X}$ objective detector was selected. Specimen-to-source and specimen-to-detector distances varied slightly with each set-up but were typically $55 \mathrm{~mm}$ and $145 \mathrm{~mm}$, respectively. An appropriate filter was applied to monochromate the x-ray beam and minimise artefacts. A $2 \times 2$ camera binning mode was used to capture the images at exposure times per projection ranging between $18 \mathrm{~s}$ and $30 \mathrm{~s}$. These parameters allowed a spatial resolution of about $1.6 \mu \mathrm{m}$ to be achieved, which was considered adequate for the resolution of cracks and openings. For each specimen, a total of up to 2401 projections were acquired over a rotation span of 180 degrees.

Up to twelve tomography datasets were acquired over 1,245,202 cycles. A second wire-bonded test coupon was imaged after 2.1 million cycles and 
cross-sectioned to provide correlative analysis through optical metallography and scanning electron microscopy (SEM).

The 2401 projection images were reconstructed using Xradia 3D Reconstructor software, which uses a filtered back projection algorithm. The reconstruction procedure included determining the centreshift, that is, the offset in pixels of the rotational axis from the centre column of the detector, and occasionally applying a correction for beam hardening. The tomography datasets were visualised and multiple virtual cross-sections were obtained using Xradia-Zeiss 3D Viewer. Further visualisation, semi-quantitative area, and volume analyses were carried out using the FIJI software package. A simple methodology was employed to quantify the evolution of damage in the first bonds. This involved estimation of the contact area resolvable within representative two-dimensional greyscale TIFF images parallel to the bond interface (in the $X-Y$ plane). This was performed using the polygon selection tool within FIJI software. The exterior surfaces of the bonds were also studied using scanning electron microscopy.

\section{Metallurgical Cross-Sections for Optical Mi- croscopy}

A separate sample, also subjected to 2.1 million power cycles under the same regime, was sectioned to provide specimens of the $X-Y$ plane and $Y-Z$ plane. These were mounted in edge-retentive epoxy resin and cured at room temperature for $24 \mathrm{~h}$. They were then slowly and carefully mechanically polished on a Buehler Metaserv automatic polisher. This involved successive grinding with 1200, 2500, and 4000 grit silicon carbide papers, and $3 \mu \mathrm{m}$ and $1 \mu \mathrm{m}$ diamond slurries, all the while ensuring that damage from successive grinding/polishing steps was completely removed before progressing. A final polish was achieved using a $0.06 \mu \mathrm{m}$ colloidal silica suspension.

\section{RESULTS AND DISCUSSION}

\section{Description of the Evolving Damage}

The regions of interest are indicated in Fig. 3 in a three-dimensional volume rendered overview of a typical specimen and consists of pairs of stitch and first bonds. Alongside this, a two-dimensional

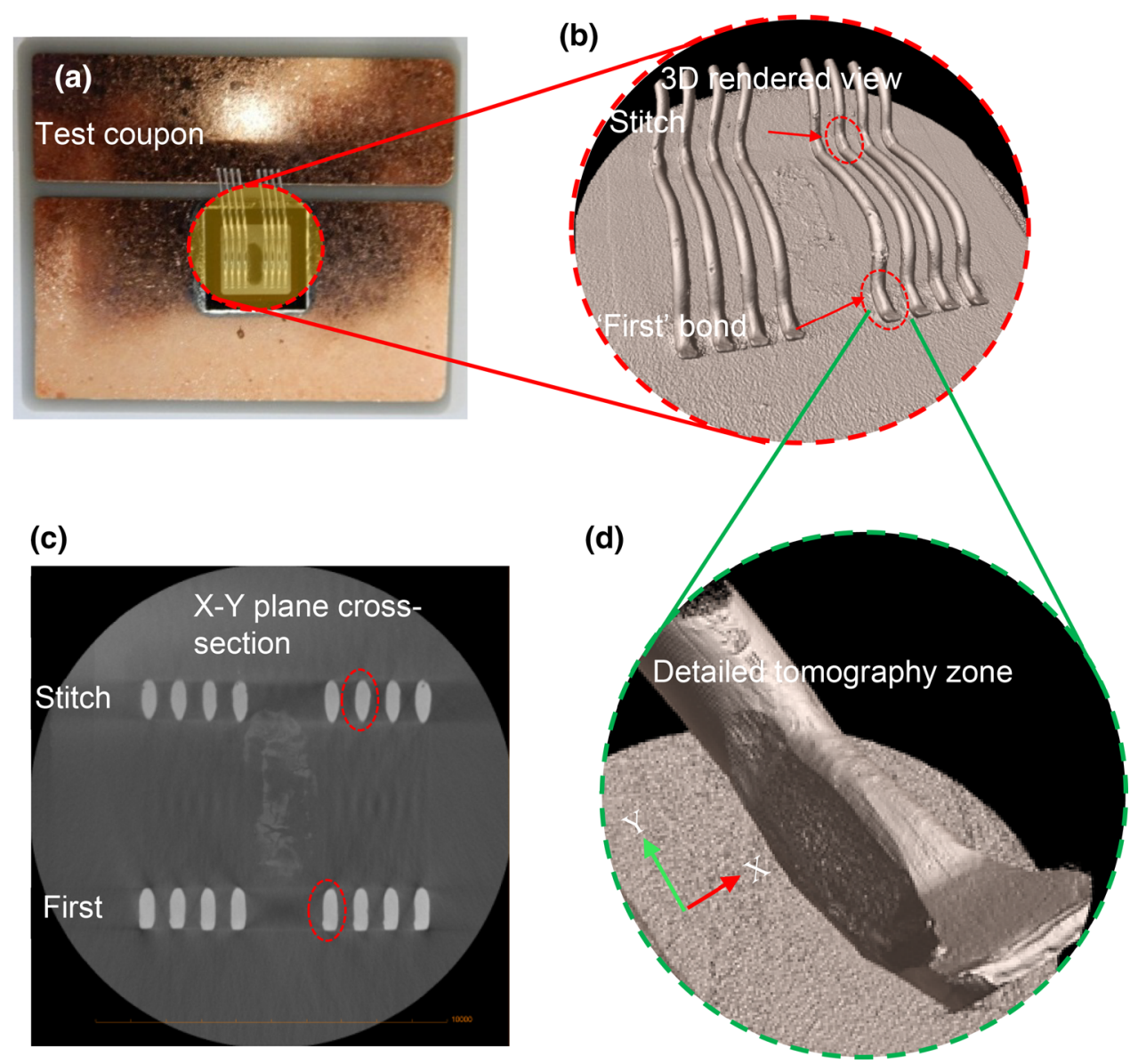

Fig. 3. Figure showing (a) the test coupon, (b) a 3-D rendered overview, (c) a 2-D virtual cross-section of tomography imaging zones, and (d) a 3-D rendered view of a typical detailed tomography zone. 
virtual cross-section is presented indicating the regions of interest in the plane of the diode and shows the orientation of the sample with reference to the direction of the incident x-rays. Two bond interfaces, i.e., one 'first' bond and one 'stitch' bond,
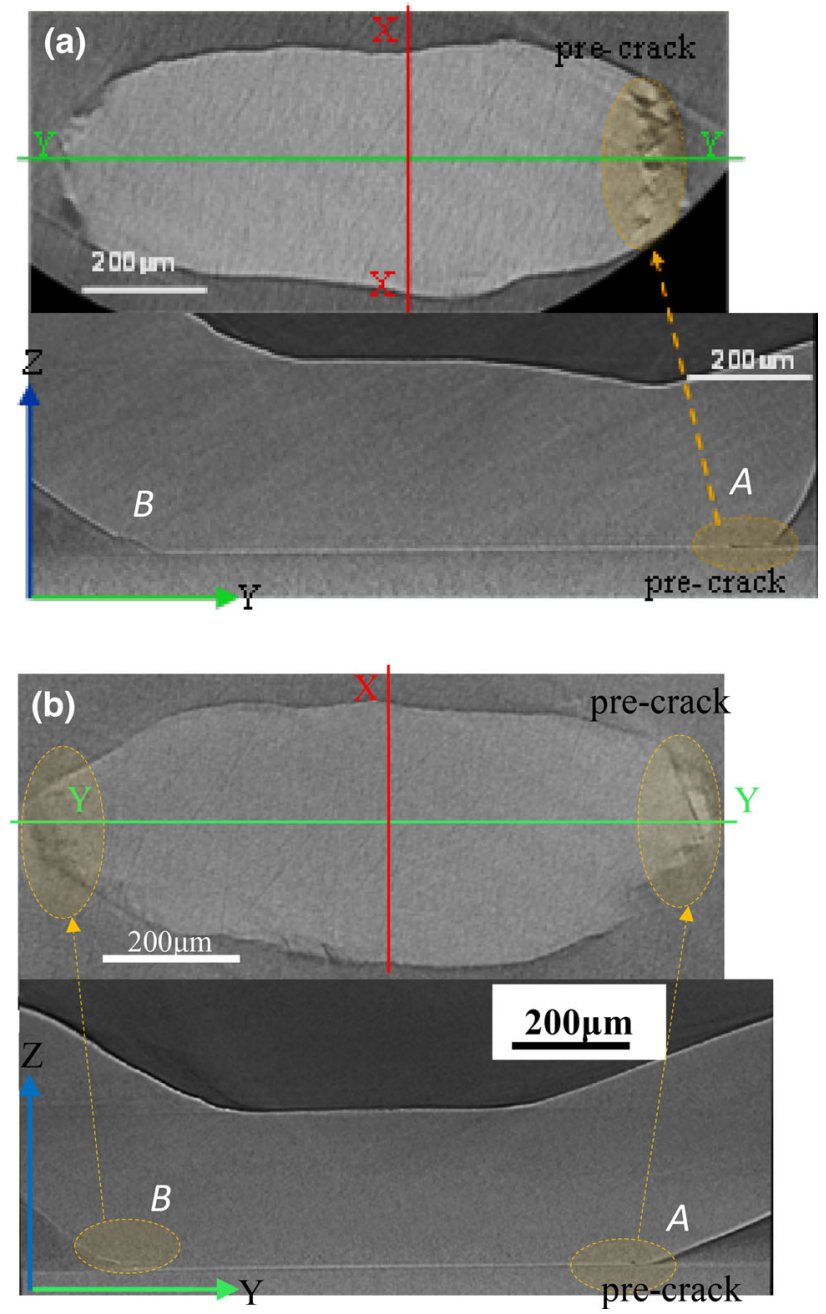

Fig. 4. Virtual cross-sections in different planes are presented for (a) 'first' bond and (b) stitch bond prior to cycling. are selected for detailed scrutiny; these are circled in Fig. 3.

\section{First Bonds}

In Fig. 4, virtual cross-sections in different planes are presented of a stitch and a 'first' bond prior to cycling. The $X-Y$ plane images show shell-nut shaped footprints typical for wire bonds and often observed after shear testing or lift-off events. ${ }^{26,30} \mathrm{~A}$ pre-cracked area is visible at the bond tail end on the right hand side of both bonds (these are highlighted and annotated $\boldsymbol{A}$ in Fig. 4). For ease of interpretation of this and subsequent virtual crosssections, it may be helpful to refer to the schematic representation in Fig. 5; this shows the first and stitch bonds and indicates the location of the bond tail, rising and falling heel regions. In both the 'first' and the 'stitch' bonds, there is also a small crack at the extremity beneath the rising heel (annotated as $\boldsymbol{B})$. Corresponding $Y-Z$ plane cross-sections are also presented and give a different and perhaps more familiar perspective of the pre-existing cracks. It is usual to find cracks at the heel of a bond prior to thermal cycling. They are thought to arise from wire flexure during bonding. ${ }^{31}$ Apart from these precracks, the interfaces of both the first and stitch bond appear defect-free in the as-bonded condition. The plane parallel to the interface (the $X-Y$ plane) is of most interest as it gives the best overview of damage evolution. Hereafter, pairs of $X-Y$ plane cross-sections from different distances above the interface are presented.

As Fig. 6a shows, there is little change observable in the first bond after 20k cycles. The initial precracked area observed in the as-bonded condition beneath the rising heel is noticeable and develops in subsequent datasets (Fig. 6b-f). After 52k cycles, there are a couple of new observations: a small new crack has appeared at the left hand longitudinal periphery. Also interestingly, more cracks emerge in the region beneath the rising heel. By $121 \mathrm{k}$ cycles, the damage both near the tail and the rising heel progress noticeably. Near the rising heel, the initially observed cracks have increased and formed

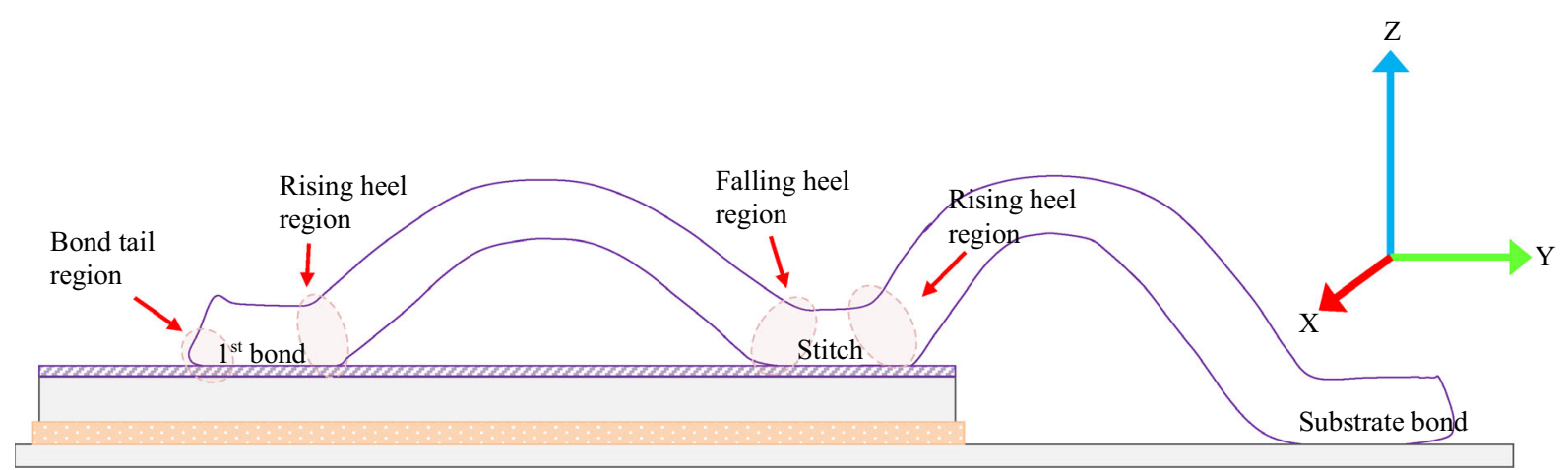

Fig. 5. Schematic diagram showing rising and falling heel regions and the tail of the first bond. 

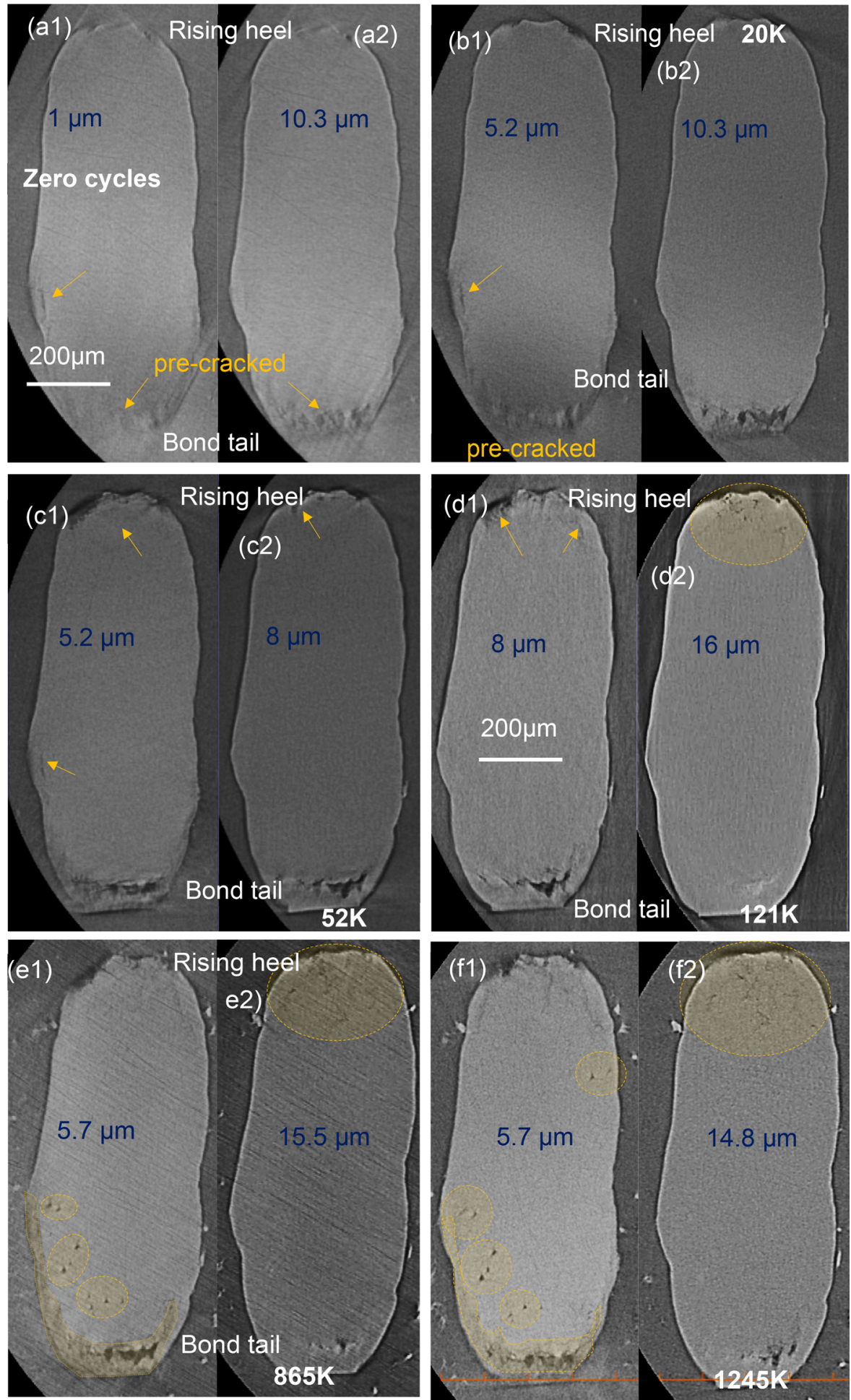

Fig. 6. Virtual cross-sections of the 'first' bond in the $X-Y$ plane (parallel to the bonding interface), showing damage evolution in the same sample at different distances from the bond interface (as indicated) with increasing number of cycles. (a1, a2) zero cycles, (b1, b2) 20,000 cycles, (c1, c2) 52,000 cycles, (d1, d2) 121,000 cycles, (e1, e2) 865,000 cycles, (f1, f2) 1,245,000 cycles.

networks, and as Fig. 6d shows, this network of cracks extends a few microns above the interface into the bulk of the wire and appear to be intergranular in nature, as expected. Interestingly, the virtual cross-sections after $865 \mathrm{k}$ cycles show the emergence of a few small but deep voids within the interior of the interface. After $1245 \mathrm{k}$ cycles, yet more voids develop in a different region (Fig. 6f). 

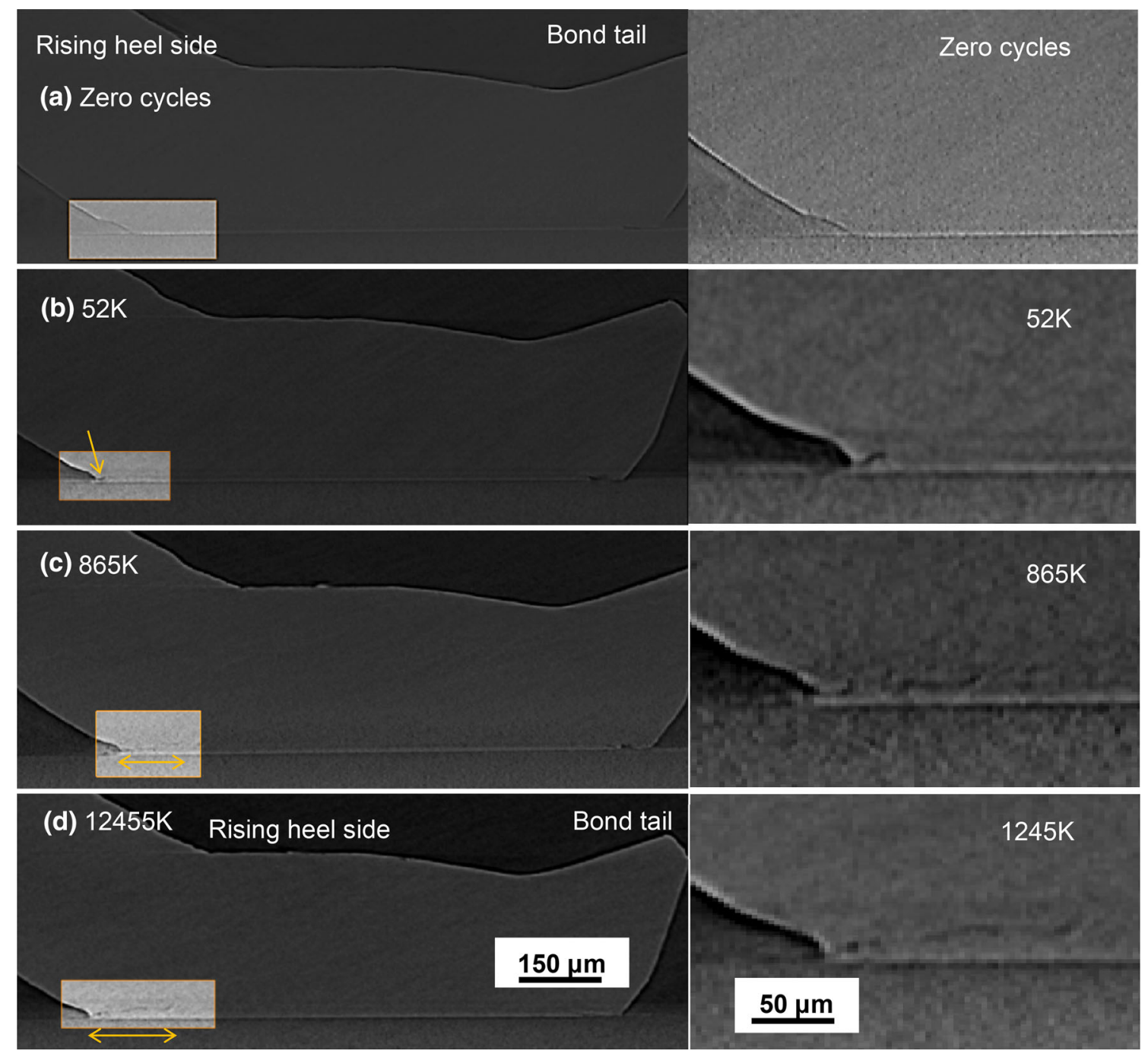

Fig. 7. Virtual cross-sections of the 'first' bond in the $Y-Z$ plane at mid thickness, showing crack growth in the same sample with increasing number of cycles (enlarged rising heel side cracks are shown on the right) (a) zero cycles, (b) 52,000 cycles, (c) 865,000 cycles, (d) $1,245,000$ cycles.

Besides the development of voids, the fine crack networks at the extremity near the rising heel are yet more prominent now extending over an increased depth of $16 \mu \mathrm{m}$ into the bulk of the wire. A series of virtual cross-sections in the $Y-Z$ plane is presented in Fig. 7 and also shows these developing cracks. Crack development is notably more rapid at the rising heel end than at the bond tail end. The cracks may extend further than is resolvable in these images.

\section{Stitch Bonds}

As with the first bond, apart from small areas of discontinuity at the extreme ends, the interior of the stitch bond is more or less featureless in the asbonded condition (see Fig. 8a-d). Cracks, however, seem more prominent earlier, at $20 \mathrm{k}$ cycles, as Fig. $8 \mathrm{~b}$ shows. Additionally, unlike the first bond, the development of cracks is rapid at both extreme ends of the bond (both rising and falling heel ends, refer to the schematic diagram in Fig. 5) although it is more pronounced at the rising heel side. A difference in the nature of damage between the two ends is observable. Damage development in the rising heel is much like that in the region beneath the rising heel of the first bond in that it is characterised by networks of cracks, which form branches and extend as the number of cycles increases. On the other hand, the development of cracks at the falling heel side is less striking.

\section{Interpretation and Analysis of Tomography Results}

In order to explain the macrostructural changes observed, it is helpful to recall bond wire microstructures, and how they evolve during 

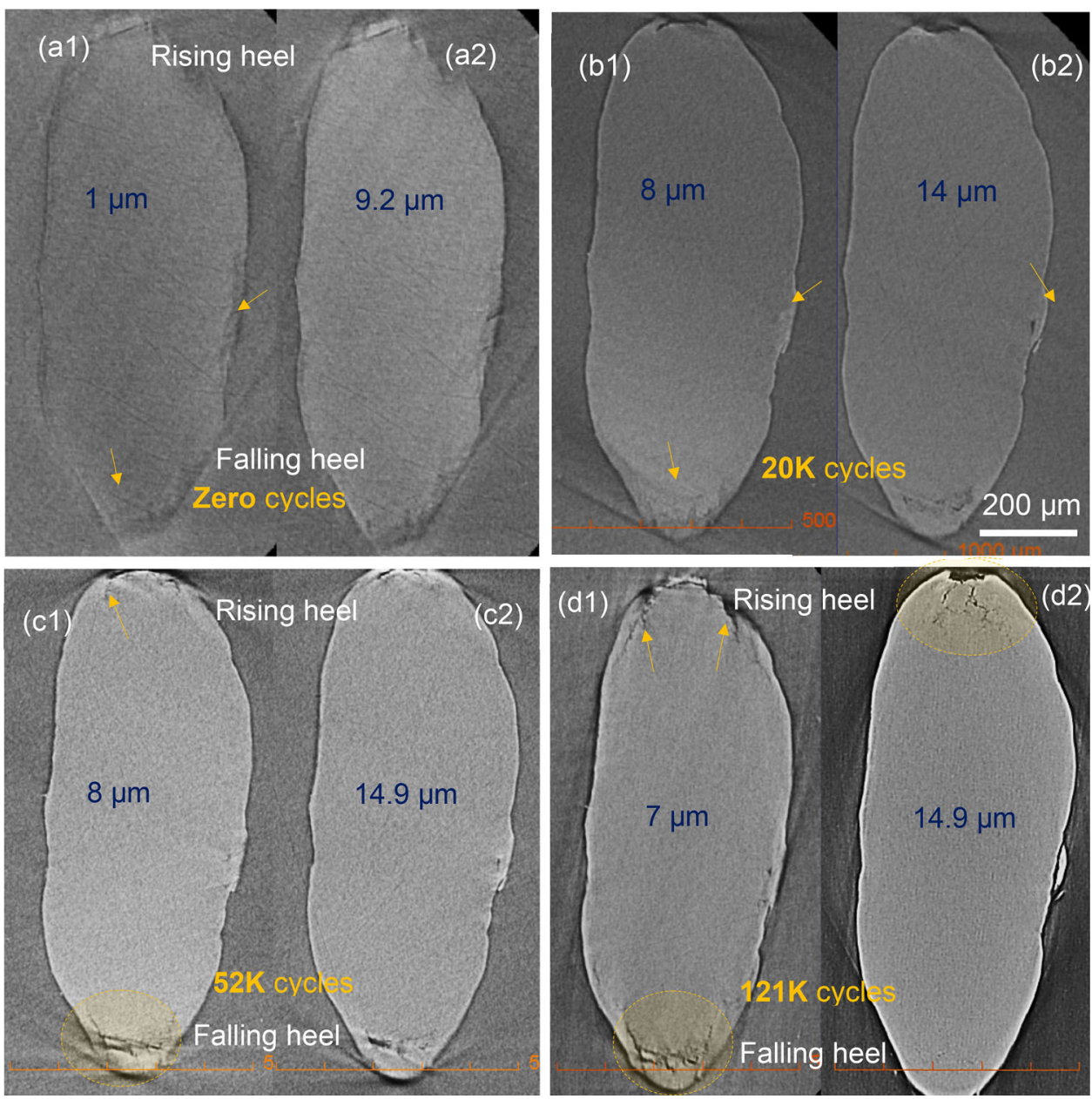

Fig. 8. Virtual cross-sections of the 'stitch' bond in the $X-Y$ plane (parallel to the bonding interface), showing damage evolution in the same sample at different distances from the bond interface (as indicated) with increasing number of cycles. (a1, a2) zero cycles, (b1, b2) 20,000 cycles, (c1, c2) 52,000 cycles, (d1, d2) 121,000 cycles.

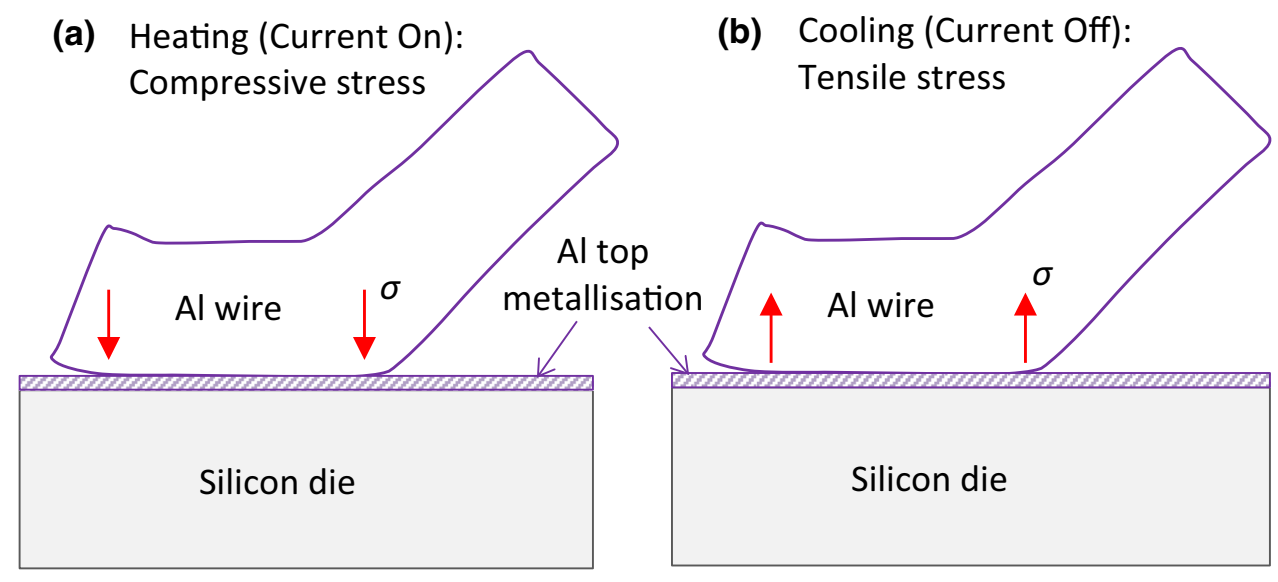

Fig. 9. Schematic diagram showing the regions of compression/tension during cycling (after Onuki et al. ${ }^{4}$ ).

cycling. The bonding process by which wire bond interconnections are produced utilises ultrasonic energy and mechanical force, which both deform the wire and facilitate plastic flow across the interface.
The work done during bonding leads to the generation of defects, i.e., dislocations, and a highly heterogeneous and deformed microstructure. ${ }^{32}$ This microstructure has been characterised as deformed 

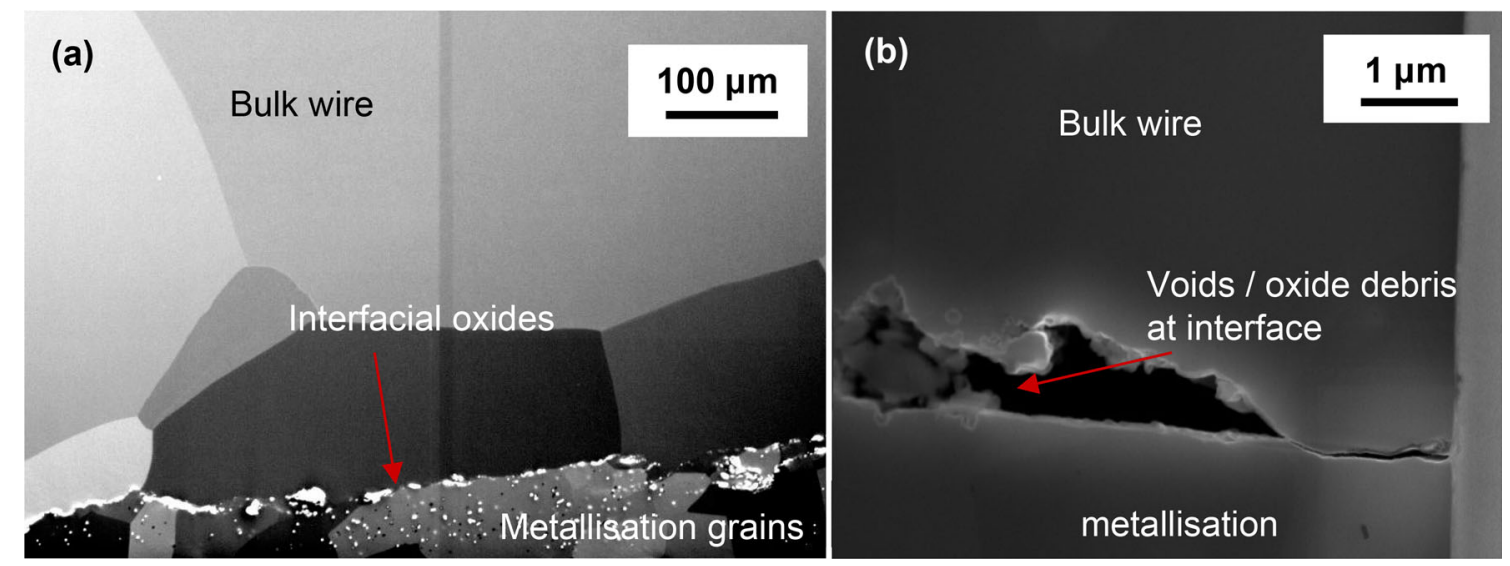

Fig. 10. Focused ion beam cross-sectional image of an as-bonded wire (a), showing interfacial oxide particles and voids (b) from Loh et al. ${ }^{44}$

elongated grains with a high degree of misorientation near the interface ${ }^{25}$ relative to the direction of the applied stress, suggestive of an increased amount of stored energy. ${ }^{33}$ The rearrangement or annihilation of these defects will serve to minimise the energy of the system and is the origin of the thermodynamic driving force for recrystallisation. Recrystallisation occurs partially at the time of bonding, as the bonding deformation is high enough to bring about the nucleation of new grains. ${ }^{34}$ During the operation of power modules, heat is generated within the semiconductor chips and switching leads to repeated heating and cooling. The aluminum wire and silicon chip expand at different rates, and this generates shear stresses at their interface. Given sufficient thermal energy, high stacking fault energy materials like aluminum readily undergo recovery (even at room temperature, ${ }^{33}$ ), during which dislocations are reconfigured into a lower energy state. Therefore, microstructural restoration under even this small temperature cycling range and relatively low maximum junction temperature would be unsurprising.

Microstructurally, the bond interface is characterised by distinctive gradients: the metallisation layer is usually distinct from the wire and made up of very fine deformed grains; directly above, there is a region of small recrystallised grains, and further away into the bulk, there are more randomly oriented grains with texture similar to that of the as-received wire. ${ }^{25,34}$ The shear stresses generated at the interface during thermal cycling are concentrated at the extreme ends of the bonded area. Driven by the release of energy, cracks develop and propagate toward the centre of the bond and in a region a few microns above the metallisation formerly characterised by fine recrystallised grains, and a region with reported high grain misorientation. ${ }^{25,34}$ This would be in agreement with the findings of this study, in which undulating cracks at least $18 \mu \mathrm{m}$ above the interface are observed and which advance toward the centre as the number of cycles increases. High angle grain boundaries are associated with the preferential initiation and propagation of fatigue cracks in fcc polycrystals. 35,36

The bond peripheries and extremities are susceptible to damage for a number of reasons. During bonding, as the wire flexes with the movement of the bond-head during loop formation damage occurs, particularly at the rising heel. Further alteration and deformation of microstructure in these regions occurs as a result of power cycling, during which the region above the heel experiences alternate compression and tension due to heating and cooling ${ }^{6}$ (see Fig. 9). Finite element simulations of bond wires during thermal cycling confirm stress concentration at the heel. ${ }^{37,38}$ During active power cycling, an exacerbation of this stress state may occur as a result of forces due to the electromagnetic interaction between the wires leading to lateral displacements. ${ }^{39}$ Concurrently, the concentration of stress in the aforesaid regions may mean a greater propensity for microstructural restoration in order to achieve a minimised energy state. Such restoration may create regions of localised low yield strength, leading to localised mismatches in the Taylor factor of grains. ${ }^{25}$ This may explain the observed concentration of evolving damage in the vicinity of the bond heels, and the rising heels in particular, where flexing during power cycling may be more intense. ${ }^{6}$

Another factor to consider is the heterogeneous distribution of current on the die and within the wires. ${ }^{40,41}$ This may explain the different rates of degradation observed at different locations.

\section{Void Formation and Growth}

In a previous article, ${ }^{42}$ we reported the appearance of interfacial voids in a same-sample tomography study during thermal cycling from $-55^{\circ} \mathrm{C}$ to $190^{\circ} \mathrm{C}$, in which voids were observed to grow and/or coalesce to form larger areas of discontinuity. It is plausible that these voids were in existence $a$ priori and may have originated from regions of partial 

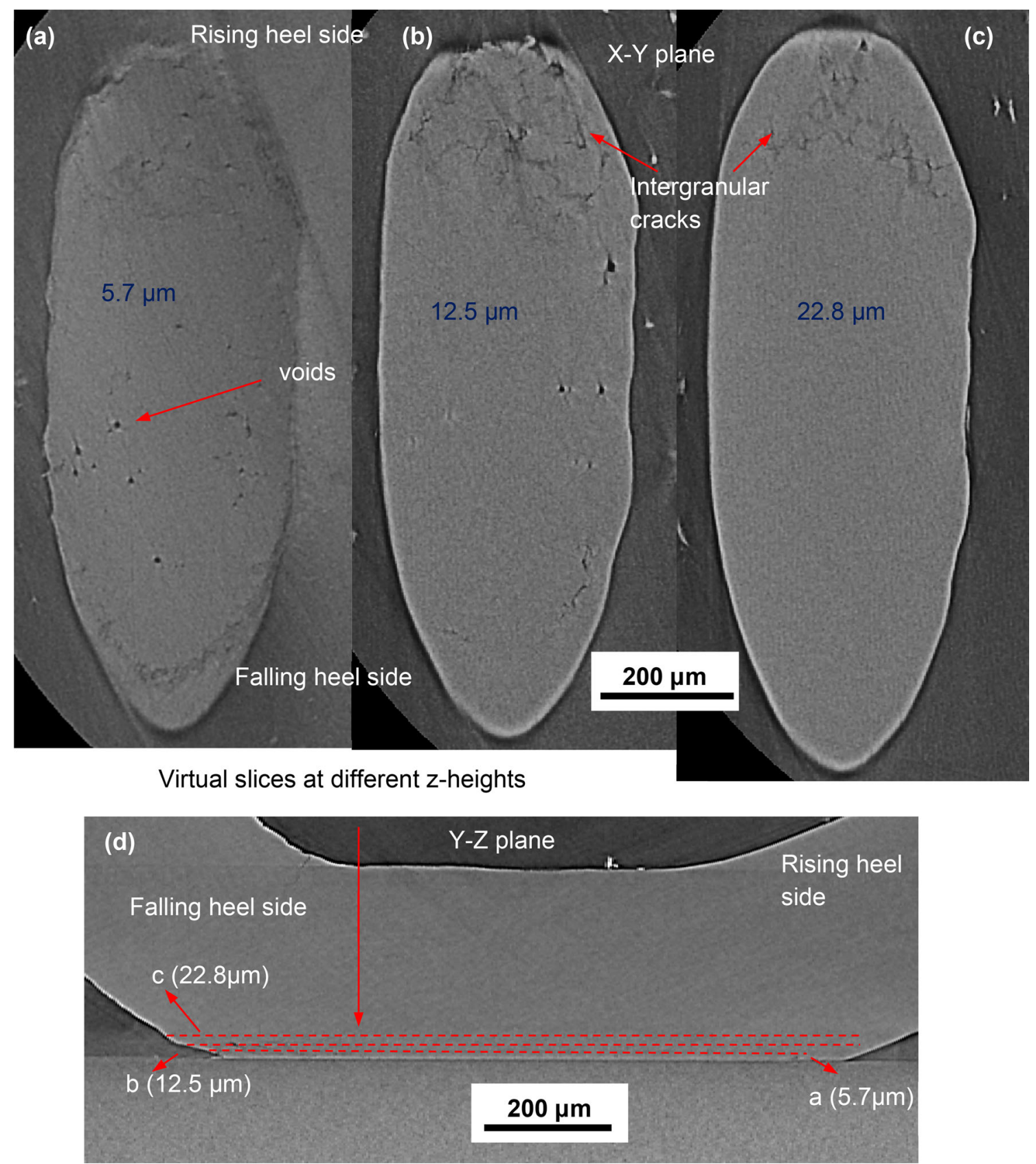

Fig. 11. Virtual cross-sections of a 'stitch' bond subjected to 2.1 million cycles, showing damage in the $X-Y$ plane at different distances (a-c) (as indicated) from the bonding interface in the $Y-Z$ plane image (d).

bonding beyond the resolution limits of the tomography datasets. Certainly, voids have been widely observed at the interfacial line in as-bonded wires and attributed to the presence of oxide debris and extraneous particles, and linked to bonding conditions. ${ }^{43,44}$ The focused ion beam (FIB) cross-sectional image in Fig. $10^{44}$ is such an example and clearly shows a line of particles between a horizontal band of fine, metallisation grains and larger grains belonging to the bulk wire. The actual nucleation of new voids under the relatively benign temperature cycling conditions of this study is also feasible, considering the homologous temperatures involved (i.e., $0.34-0.37 T_{\mathrm{m}}$ ). While the thermally activated transport of atoms over time is certainly viable, we know that the high strain [due to coefficient of thermal expansion (CTE) mismatch at the interface in this case] can also drive the movement of atoms away from voids by dislocation loops, resulting in a gradual enlargement of the said voids. ${ }^{45}$ Thus, strain-induced void growth is strongly linked to dislocation density. ${ }^{46}$ This strain can also provide the driving force for grain boundary nucleation and grain growth. ${ }^{47}$ 

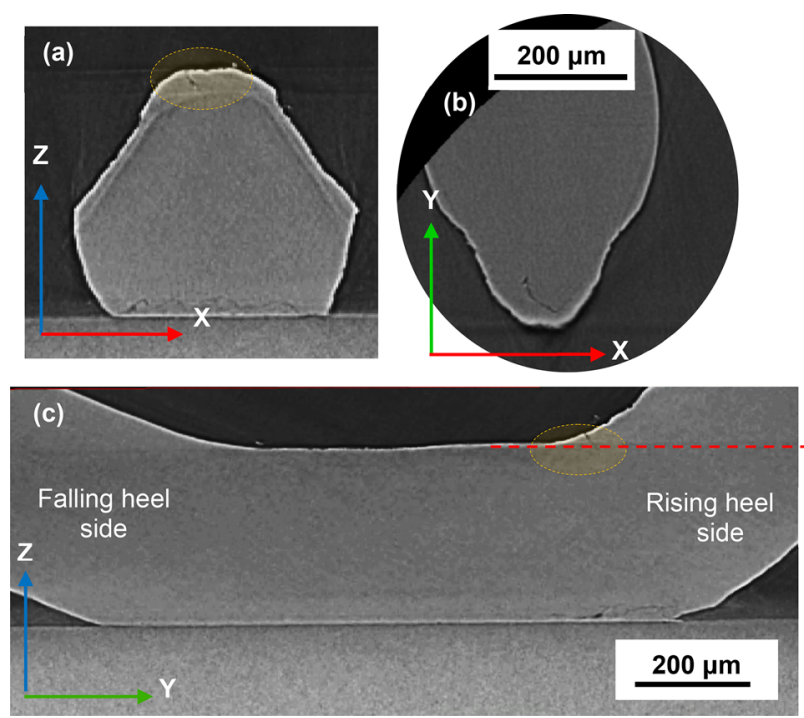

Fig. 12. Virtual cross-sections of a 'stitch' bond subjected to 2.1 million cycles, showing perspectives of an emerging heel crack in different planes (a) $X-Z$ plane, (b) $X-Y$ plane, (c) $Y-Z$ plane.

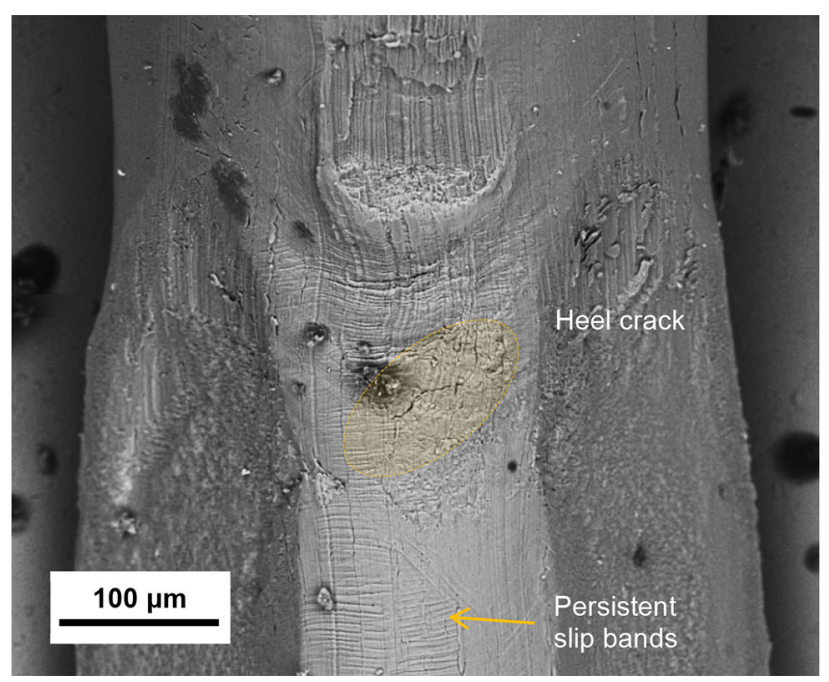

Fig. 13. SEM micrograph of a 'stitch' bond subjected to 2.1 million cycles showing the emergence of a heel crack and several slip bands on the wire bond surface.

\section{Correlative Microscopy}

A correlative microstructural study has been undertaken to look at the damage features observed in more detail, and in particular to elucidate the origin of voids, influence of surface reconstruction, and morphology in the vicinity of cracks. This study combines perspectives from the tomography with optical microscopy and SEM. Here, a separate sample, also subjected to the same power cycling regime, is investigated after 2.1 million cycles. Virtual cross-sectional images in the $X-Y$ and $Y-Z$ planes are presented in Fig. 11 . The $X-Y$ plane images show similar damage as observed in Figs. 6 and 8 , but much more vividly, due to its more advanced state of wear-out. Interior microcracks with an inter-granular appearance can be seen in the rising heel end. Several microcracks and voids are also clearly visible within the interior. Virtual cross-sections in Fig. 12 interestingly show the appearance of a small heel crack. An SEM micrograph of the same sample confirms the observation (Fig. 13). Despite the appearance of heel cracks within the bonds, the rate of crack propagation at the interface is more rapid and is expected to be the dominant failure mode.

Following tomography, two metallographic crosssections have been prepared in the $Y-Z$ plane and $X-Y$ planes. In Fig. 14, optical micrographs in the $Y-Z$ plane are presented, together with corresponding tomography images for the same sample. The crack near the rising heel is undulating and branches upward and downward along grain boundaries a few microns above the $3-4 \mu \mathrm{m}$ thick metallisation. These branches are evocative of triple junction grain boundaries. The crack at the falling heel side appears more horizontal and interfacial in character. There are also islands of discontinuity at the interface of the bond which either contain voids or extraneous particles. These can be seen in the close-up of the stitch bond microstructure presented in Fig. 14c. Some grain boundaries are visible, as are several distinctive persistent slip bands (PSBs) (see Fig. 14b). Some PSBs appear normal and others are at about $45^{\circ}$ to the bond interface. Some of the slip bands emanate from/terminate on grain boundaries or the interface between the metallisation and bulk wire. PSBs epitomise a form of localisation of plastic strain, especially that due to symmetrical cyclic deformation below $0.5 T_{\mathrm{m}} \cdot{ }^{48,49}$ According to Zhang, ${ }^{48}$ fatigue cracks tend to occur where PSBs impinge on large-angle grain boundaries. Cracks may also initiate at sites where PSBs interact with voids or extraneous inclusions. ${ }^{36}$ In the metallographic sections in the $X-Y$ plane, at approximately $20 \mu \mathrm{m}$ above the bond interface (Fig. 15), intergranular cracks akin to those first referred to in Figs. 6, 7, and 8 can be resolved with greater clarity, with hallmarks of triple-junctions. According to Kobayashi et al., ${ }^{36}$ the nucleation and propagation of fatigue cracks within high purity aluminum occur mainly along grain boundaries and are strongly dependent on both the grain boundary morphology and configuration with respect to the persistent slip bands. The fact that these deformation substructures, which are usually associated with low cycle fatigue, are observed under small temperature fluctuation (often considered analogous to high cycle fatigue and elastic strain) would suggest two possible factors. Firstly, temperature plays a significant part in driving the degradation process; secondly, local stress concentrations specific to electrically-driven load-cycling influence local plastic deformation. An important implication of these findings is that thermomechanical fatigue 

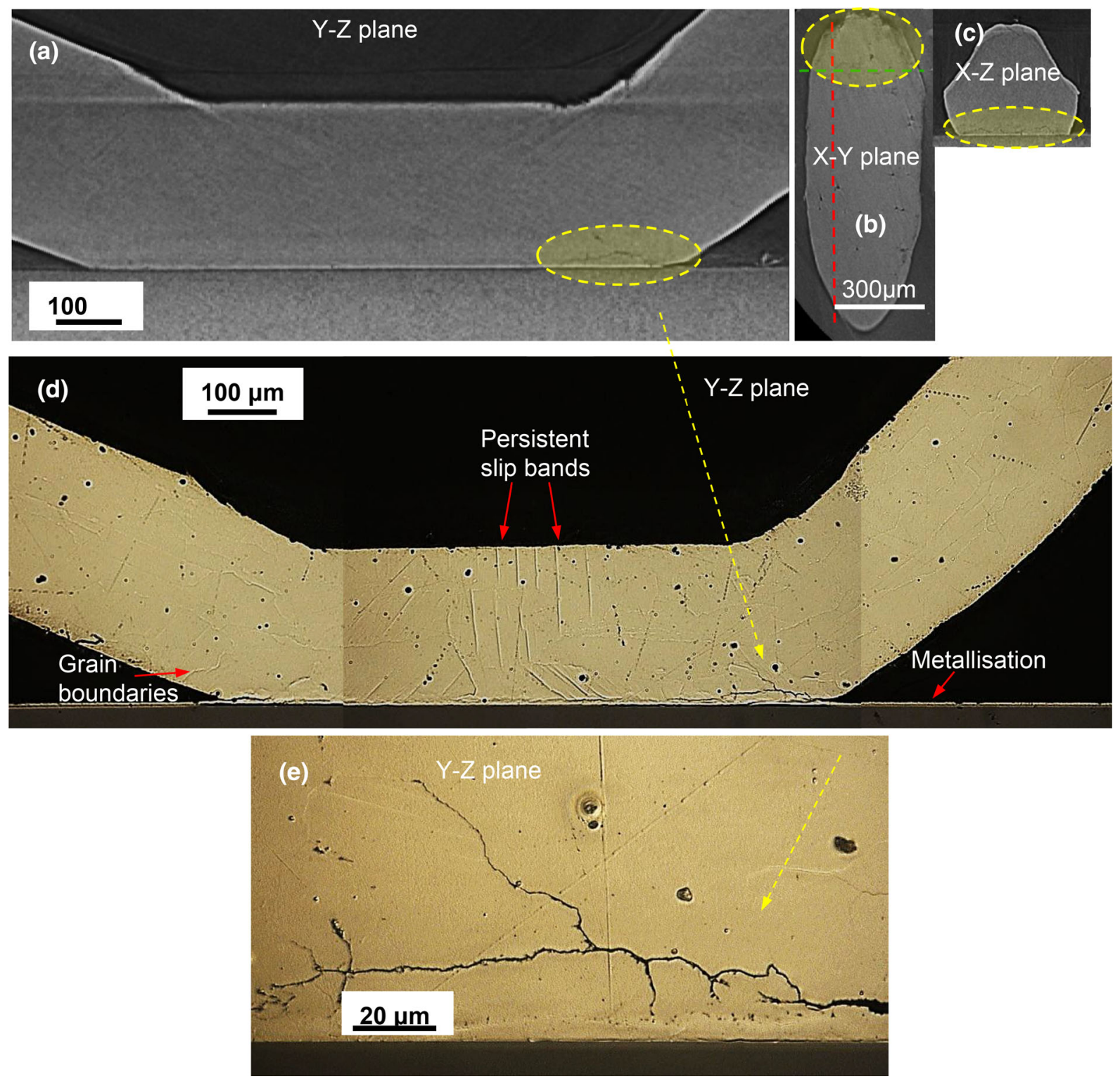

Fig. 14. Virtual cross-section in the (a) $Y-Z$, (b) $X-Y$ and (c) $X-Z$ planes of 'stitch' bond subjected to 2.1 million cycles, and corresponding optical micrographs following metallographic preparation in the $Y-Z$ plane $(d, e)$.

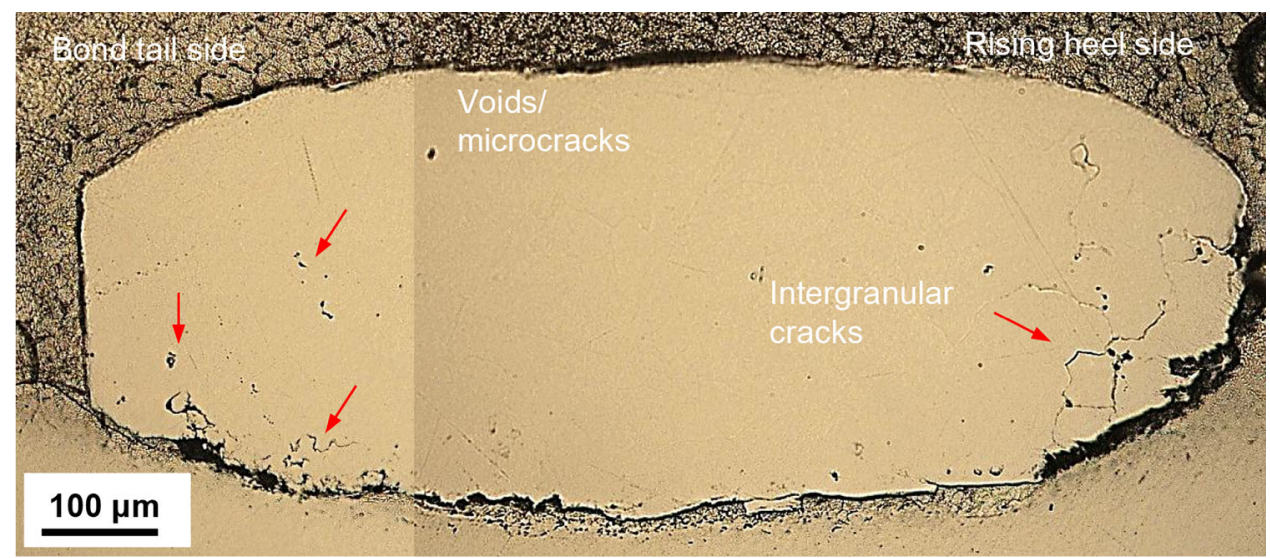

Fig. 15. Metallographic cross-section in the $X-Y$ plane (parallel to the bond interface) of a 'first' bond subjected to 2.1 million cycles. 


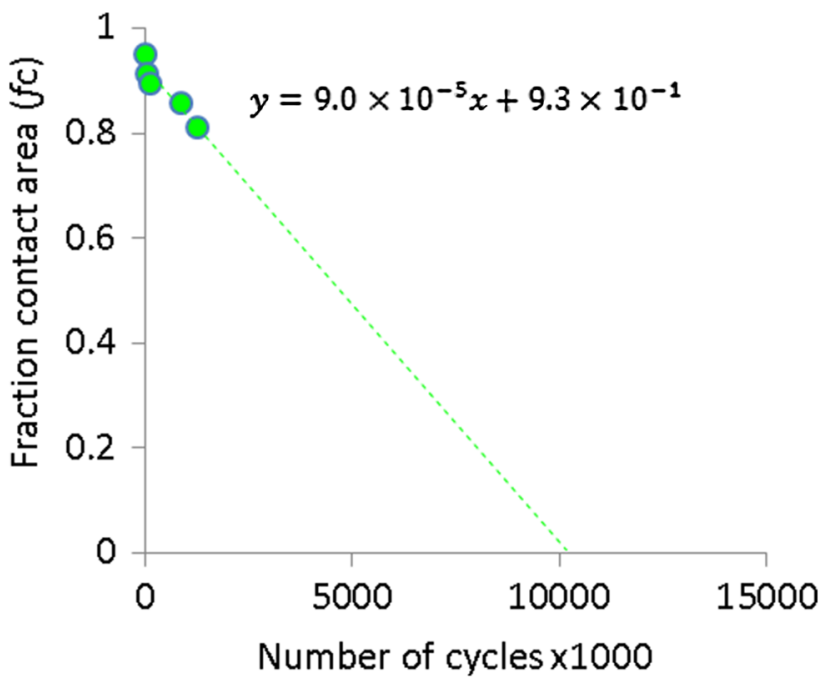

Fig. 16. Fractional bonded area bonded versus number of cycles for first bond.

requires an approach different from that of mechanical fatigue. This is especially noteworthy in relation to the interpretation of isothermal mechanical fatigue tests performed in lieu of thermomechanical tests (e.g., Refs. 9 and 50), as such tests are unable to account for the influence of thermally driven microstructural phenomena, which clearly occur even under such small loads.

\section{Estimation of Lifetime}

In Fig. 16, the evolution of damage within the first bond is expressed as the fractional contact area as a function of the number of cycles. The fraction of area bonded $f_{\mathrm{c}}$ is close to 1 in the as-bonded condition and tends to zero with an increasing number of cycles. Linear regression analysis of the data forecasts lift-off at approximately 10 million cycles. This agrees well with that of Ramminger, based on the Coffin-Manson model ${ }^{51}$ (see Fig. 17a). However, our estimation deviates markedly from the prediction of Onuki et al. ${ }^{6}$ (see Fig. 17b). The estimation in Ref. 6 was based on the behaviour of aluminum under load-controlled bending and predicted nearly infinite lifetimes below $40 \mathrm{~K}$. One reason for the disagreement of Onuki et al.'s prediction with our experimental data may be that temperature, strain-rate dependence of the wire's response to mechanical stress, and local stress concentrations associated with crack tips and voids are not reflected in load-controlled fatigue data. ${ }^{9}$ This underscores the need for life assessment models, which are not based solely on conventional understanding of isothermal mechanical fatigue, but incorporate the influence of temperature and time-dependent microstructural parameters. (a)

$\leftarrow$ S. Ramminger

$\Delta$ This paper

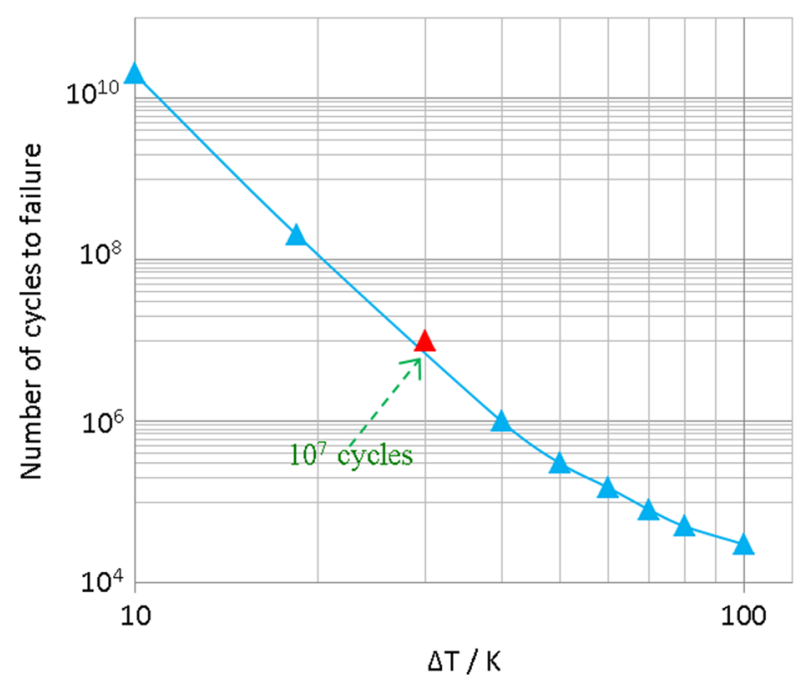

(b)

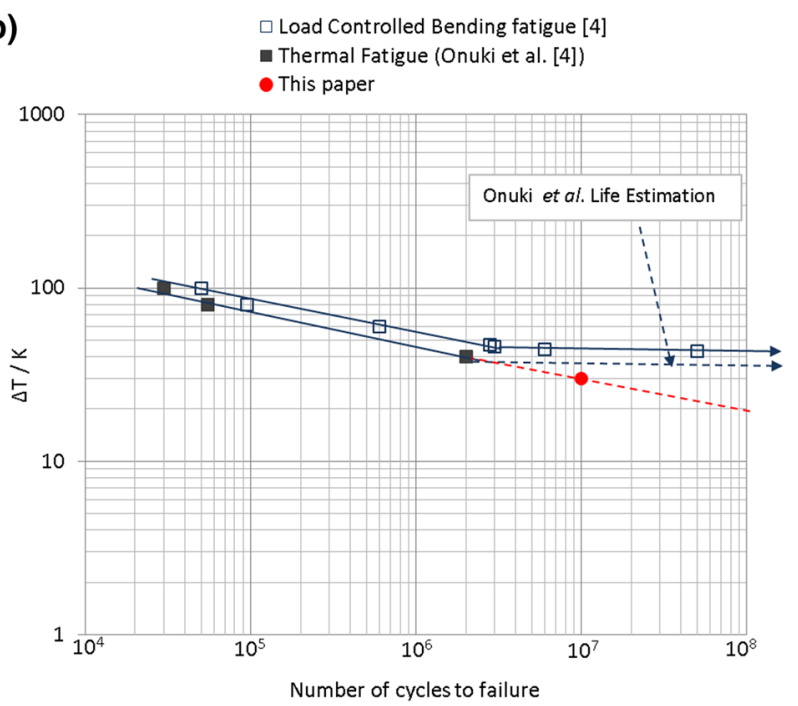

Fig. 17. Comparison of life estimation from fractional contact area with predictions in the literature (a) courtesy of Ramminger ${ }^{51}$ (b) Onuki et al. ${ }^{6}$

\section{SUMMARY AND CONCLUSIONS}

In this paper, 3-D x-ray microscopy has been utilised to visualise the evolution of cracks and voids in ultrasonically bonded aluminum wires subjected to a small junction temperature fluctuation from $40^{\circ} \mathrm{C}$ to $70^{\circ} \mathrm{C}$ under active power cycling. The development of degradation is demonstrable. Cracks were observed to emanate from the extreme edges of the bonds and advance towards the centre in an interfacial fashion. In addition, intergranular cracks were observed to occur primarily in the vicinity of the rising heel side of both the first and stitch bonds. Furthermore, micro-defects, which may be voids or micro-cracks, have been observed within the interior, growing and increasing in 
number with an increasing number of cycles. An estimation of lifetime made from measuring contact area as a function of number of cycles, together with the observed microstructural features, suggest that temperature and local stress concentrations at crack tips and voids play a significant part in driving the degradation process.

\section{ACKNOWLEDGEMENTS}

The authors gratefully acknowledge the support of the Innovative Electronics Manufacturing Research Centre (IeMRC) funded by the UK Engineering and Physical Sciences Research Council (EPSRC) through research Grant EP/H03014X/1. The authors also wish to thank Dynex Semiconductor Ltd. for providing the wire bond samples.

\section{OPEN ACCESS}

This article is distributed under the terms of the Creative Commons Attribution 4.0 International License (http://creativecommons.org/licenses/by/4.0/), which permits unrestricted use, distribution, and reproduction in any medium, provided you give appropriate credit to the original author(s) and the source, provide a link to the Creative Commons license, and indicate if changes were made.

\section{REFERENCES}

1. M. Musallam, C.M. Johnson, C.Y. Yin, H. Lu, and C. Bailey, in 13th International Power Electronics and Motion Control Conference (2008), pp. 76-83.

2. B. Ji, V. Pickert, W. Cao, and B. Zahawi, IEEE Trans. Power Electron. 28, 5568 (2013).

3. Y. Yamada, Y. Takaku, Y. Yagi, I. Nakagawa, T. Atsumi, M. Shirai, and I. Ohnuma, Microelectron. Reliab. 47, 2147 (2007).

4. R. Bayerer, Microelectron. Reliab. 50, 1715 (2010).

5. R. Amro and J. Lutz, in Proc. 2004 35th Annual IEEE Power Electronics Specialists Conference (2004), pp. 2593-2598.

6. J. Onuki, M. Koizumi, and M. Suwa, IEEE Trans. Adv. Pack. 23, 108-112 (2000).

7. J. Wu, L. Zhou, P. Sun, and X. Du, in Proc. Electronics and Application Conference and Exposition (PEAC), 2014 International (2014), pp. 41-48.

8. K. Sasaki and N. Iwasa, in Proc. 20th Int. Symp. Power Semicond. Devices ICs (2008), pp. 181-184.

9. G. Khatibi, M. Lederer, B. Weiss, T. Licht, J. Bernardi, and H. Danninger, Proc. Eng. 2, 511 (2010).

10. M. Held, P. Jacob, G. Nicoletti, P. Scacco, and M.H. Poech, Int. J. Electron. 86, 1193 (1999).

11. U. Scheuermann and R. Schmidt, Microelectron. Reliab. 53, 1687 (2013).

12. P. Cova and F. Fantini, Microelectron. Reliab. 38, 1347 (1998).

13. P.A. Agyakwa, V.M.F. Marques, M.R. Corfield, J.F. Li, L. Yang, and C.M. Johnson, J. Electron. Mater. 42, 537 (2013).

14. L. Zhou, S. Zhou, and M. Xu, Microelectron. Reliab. 53, 282 (2013).

15. K.B. Pedersen, P.K. Kristensen, V. Popok, and K. Pedersen, IEEE Trans. Power Electron. 30, 2405 (2015).

16. P.J. Withers and M. Preuss, Annu. Rev. Mater. Res. 4, 81 (2012).

17. M. Ciappa, Microelectron. Reliab. 42, 653 (2002).
18. I. Lum, M. Mayer, and J. Zhou, J. Electron. Mater. 35, 433 (2006).

19. S. Ramminger, S.P. Turkes, and G. Wachutka, Microelectron. Reliab. 38, 1301 (1998).

20. J.E. Krzanowski, IEEE Trans. Compon. Hybrid 13, 176 (1990).

21. I. Lum, M. Mayer, and Y. Zhou, J. Electron. Mater. 35, 433 (2006).

22. K.C. Joshi, Weld. J. 50, 840 (1971).

23. R. Pohlman and E. Lehfeldt, Ultrasonics 4, 178 (1966).

24. N. Murdeshwar and J.E. Krzanowski, Metall. Mater. Trans. A 28, 2663 (1997).

25. M.S. Broll, U. Geißler, J. Höfer, S. Schmitz, O. Wittler, and K.D. Lang, Microelectron. Reliab. (2015). doi: 10.1016/j.microrel.2015.03.002.

26. K.B. Pedersen, D. Bening, P.K. Kristensen, V. Popok, and K. Pedersen, J. Mater. Sci. 25, 2863 (2014).

27. Y. Murakami and K.J. Miller, Int. J. Fatigue 27, 991 (2005).

28. P.J. Withers, Nat. Mater. 12,7 (2013).

29. J.Y. Buffiere, E. Maire, J. Adrien, J.P. Masse, and E. Boller, Exp. Mech. 50, 289 (2010).

30. T. Matsunaga and Y. Uegai, in Proc. Electronics System Integration Technology Conference (2006), pp. 726-732.

31. L. Merkle, M. Sonner, and M. Petzold, Microelectron. Reliab. 54, 417 (2014).

32. U. Geißler, M. Schneider-Ramelow, and H. Reichl, IEEE Trans. Compon. Pack. Technol 32, 794 (2009).

33. R.D. Doherty, D.A. Hughes, F.J. Humphreys, J.J. Jonas, D. Juul Jensen, M.E. Kassner, W.E. King, T.R. McNelley, H.J. McQueen, and A.D. Rollett, Mater. Sci.Eng. A238, 219 (1997).

34. J.E. Krzanowski, IEEE Trans. Compon. Hybrid 13, 176 (1990).

35. Z.F. Zhang and Z.G. Wang, Prog. Mater. Sci. 53, 1025 (2008).

36. S. Kobayashi, T. Inomata, H. Kobayashi, S. Tsurekawa, and T. Watanabe, J. Mater. Sci. 43, 3792 (2008).

37. H. Lu, W.-S. Loh, C. Bailey, and C.M. Johnson, in 3rd International Microsystems, Packaging, Assembly \& Circuits Technology Conference (2008), pp. 22-24. doi:10.1109/ IMPACT.2008.4783883.

38. T.Y. Hung, L.L. Liao, C.C. Wang, W.H. Chi, and K.N. Chiang, IEEE TDMR 14, 484 (2014).

39. H. Medjahed, P.-E. Vivad, and B. Nogarede, in Proc. 6th International Conference on Integrated Power Systems (CIPS) (2012).

40. B. Czerny, M. Lederer, B. Nag, A. Trnka, G. Khatibi, and M. Thoben, Microelectron. Reliab. 52, 2353 (2012).

41. T.Y. Hung, S.Y. Chiang, C.J. Huang, C.C. Lee, and K.N. Chiang, Microelectron. Reliab. 51, 1819 (2011).

42. P.A. Agyakwa, L. Yang, M.R. Corfield, and C.M. Johnson, in Proc. 8th International Conference on Integrated Power Systems (CIPS) (2014).

43. G. Khatibi, B. Weiss, J. Bernadi, and S. Schwarz, J. Electron. Mater. 41, 3436 (2012).

44. W.-S. Loh, S.C. Hogg, R.J. Ikujeniya, M.R. Corfield, P. Agyakwa, and C.M. Johnson, in Proc. International Conference on High Temperature Electronics (HiTEC) (Albuquerque, 2008).

45. C. Mi, D.A. Buttry, P. Sharma, and D.A. Kouris, J. Mech. Phys. Solids 59, 1858 (2011).

46. P. Shanthraj and M.A. Zikry, Int. J. Plast. 34, 154 (2012).

47. R.R. Keller, R.H. Geiss, N. Barbosa, A.J. Slifka, and D.T. Read, Metall. Mater. Trans. A 38, 2263 (2007).

48. Z.J. Zhang, P. Zhang, L.L. Li, and Z.F. Zhang, Acta Mater. 60, 3113 (2012).

49. P. Lukas and L. Kunz, Philos. Mag. 84, 317 (2004).

50. G. Khatibi, W. Wroczewski, B. Weiss, and T. Licht, $M i$ croelectron. Reliab. 48, 1822 (2008).

51. S. Ramminger, Siemens AG, Munich, Germany, personal communication, 2008. 